\title{
POPULATION CHARACTERISTICS OF BIG BROWN BAT AND ARIZONA MYOTIS USING ARTIFICIAL ROOSTING STRUCTURES IN NORTHERN ARIZONA
}

\author{
Joel M. Diamond ${ }^{1,4}$, R. Nathan Gwinn ${ }^{1}$, Janet Johnson², \\ Hannah Telle ${ }^{2}$, and Gabrielle F. Diamond ${ }^{3}$
}

\begin{abstract}
Big brown bats (Eptesicus fuscus) and a close relative of Arizona myotis (Myotis occultus), the little brown bat (Myotis lucifugus) in the eastern United States, are among those species experiencing unprecedented population declines related to white-nose syndrome (WNS). Determining population characteristic baselines for big brown bat and Arizona myotis is paramount in detecting population declines before they reach critical levels. We targeted 2 bat species strongly associated with ponderosa pine forests in northern Arizona. Big brown bats and Arizona myotis readily utilize human-made structures and have a cosmopolitan distribution across the ponderosa pine (Pinus ponderosa) ecosystem of northern Arizona (Adams 2003). Between 2005 and 2012 we installed artificial bat roosts at Camp Navajo near Flagstaff, Arizona. We captured bats at these roosting structures and marked them using modified bird bands. We established baseline population characteristics on Camp Navajo by utilizing a 7-year mark-and-recapture data set. We also provide a measure of population status that may be compared across temporal scales within the study area. In essence, this study provides the basis for an early warning system for WNS in Arizona.
\end{abstract}

Resumen.-El gran murciélago marrón (Eptesicus fuscus) y un pariente cercano del Myotis de Arizona (Myotis occultus), el pequeño murciélago marrón (Myotis lucifugus) típico de la zona oriental de Estados Unidos, se encuentran entre las especies que experimentan decremento sin precedentes en sus poblaciones relacionado con el síndrome de la nariz blanca (WNS, por sus siglas en inglés). Determinar las características básicas de las poblaciones de estas dos especies es de suma importancia en la detección de la disminución de la población antes de que ésta alcance niveles críticos. Nos centramos en dos especies de murciélago claramente asociadas a los bosques de pino ponderosa en el norte de Arizona. El gran murciélago marrón (Eptesicus fuscus) y el Myotis de Arizona (Myotis occultus) utilizan con gran facilidad estructuras construidas por humanos y tienen una distribución cosmopolita a lo largo del ecosistema de pinos ponderosa (Pinus ponderosa) en el norte de Arizona (Adams 2003). Entre el 2005 y 2012, se instalaron refugios artificiales para murciélagos en Camp Navajo cerca de Flagstaff, Arizona. Capturamos murciélagos en estructuras de refugio y los marcamos, utilizando bandas para aves modificadas. Establecimos las características básicas de la población en Camp Navajo utilizando datos de marca y recaptura de 7 años. También pudimos proporcionar una medida del estado de la población que puede ser comparada con las escalas temporales dentro de la zona de estudio. Básicamente, este estudio proporciona la base para un sistema de alerta temprana con respecto a la WNS en Arizona.

The ecology of the big brown bat (Eptesicus fuscus) is well understood because of its strong association with man-made structures (barns, bridges, etc.) (Adams 2003, Neubaum et al. 2005, Ellison et al. 2007, Neubaum et al. 2007, O'Shea et al. 2010). Big brown bats are beetle specialists but have also been observed opportunistically eating a wide variety of insects (Agosta 2002). Vegetation and nonflying insects have also been detected in the stomach contents of this species, indicating gleaning foraging (Whitaker 1972). In Arizona, big brown bats are associated with habitats from ponderosa pine forests to lowland desert scrub (Hoffmeister 1986, Adams 2003). Big brown bats readily switch roosts and use different roosts across reproductive periods (Lausen and Barclay 2002, Ellison et al. 2007). This species requires surface water, drinking only after the first foraging bout (Findley et al. 1975). Big brown bats breed in the fall and are gravid through the spring. Gravid females have been observed into June and lactating females detected as late as August in the western United States (Adams 2003, O'Shea et al. 2010). Western big brown bat populations are characterized by singular births, unlike eastern U.S. populations, which generally are characterized by twin births (Adams 2003, O'Shea et al. 2010). Big brown bats form

\footnotetext{
${ }^{1}$ Arizona Game and Fish Department, Wildlife Contracts Branch, 5000 W. Carefree Highway, Phoenix, AZ 85086.

2 Arizona Department of Emergency and Military Affairs, Arizona Army National Guard: Camp Navajo, Bellmont, AZ 86015.

${ }^{3}$ Westland Resources, Inc., 4001 E. Paradise Falls Drive, Tucson, AZ 85712.

${ }^{4}$ E-mail: jdiamond@azgfd.gov
} 
maternity colonies ranging from tens to hundreds in the warm season (Wilson and Ruff 1999, Neubaum et al. 2007). These maternity colonies are characterized by congregations of females and juveniles. Although the summer ecology of this species is well understood, little is known about the winter ecology of this species in the west. Big brown bats are known to hibernate in small colonies or singularly in caves, mines, and synthetic roosting structures, but few natural hibernacula are known (Kurta and Baker 1990, Neubaum et al. 2006). Thus, any catastrophic mortality event impacting big brown bat populations in northern Arizona during the hibernation period would go undetected until the warm season.

Until recently, the Arizona myotis (Myotis occultus) was classified as a subspecies of the little brown bat (Myotis lucifugus) (Piaggio et al. 2002). Arizona myotis use open water for foraging and feeding (Findley et al. 1975). Prey include mayflies, caddisflies, midges, and mosquitoes (Adams 2003). Arizona myotis forage over water, among trees, and in forest clearings. This species, like the big brown bat, utilizes a high diversity of roosting types, from buildings and bridges to mines and caves (Wilson and Ruff 1999). Arizona myotis breed in the fall and are gravid through spring, giving birth from May to July (Adams 2003). Females continue to feed the young after volancy from July to September (Fenton and Barclay 1980). Although little is known about the wintering ecology of the Arizona myotis, we can infer several factors from its former conspecific, the little brown bat. Little brown bats hibernate during the winter months across their range (Adams 2003). Females of this species have been documented traveling $>100 \mathrm{~km}$ between summer roosts and the hibernacula (Wilson and Ruff 1999). As with the big brown bat, little is known about the winter ecology of the little brown bat and no hibernacula are known for this species in Arizona (A. McIntire, Arizona Game and Fish Department, Bat Coordinator, personal communication). Therefore, any catastrophic mortality event would go undetected until the warm season.

Although the warm season distribution and ecology of both species have been studied in northern Arizona, the population characteristics of these 2 species is poorly understood
(Warner 1985, Hoffmeister 1986, Rabe et al. 1998). The big brown bat and a close relative of Arizona myotis, the little brown bat in the eastern United States, are among those species experiencing the most profound population declines related to white-nose syndrome (WNS; Blehert et al. 2009). Although this psychrophilic fungus has yet to reach the western United States, determining population characteristic baselines for big brown bat and Arizona myotis is paramount in detecting the presence of population declines. In the eastern United States, many hibernacula for these species are known, and detection of WNS occurs through repeated surveys at the hibernacula. Management agencies in Arizona have yet to discover any hibernacula for these 2 species. Therefore, detection of WNS in the populations of these 2 species in Arizona will likely come through a change in the population characteristics of these species during the warm season. However, the population characteristics for these species have yet to be determined. Our objectives for this study were twofold. The first objective was to establish baseline population characteristics on Camp Navajo, a National Guard installation in northern Arizona, by utilizing a 7-year mark-andrecapture data set. The second objective was to provide a measure of population status that may be compared across temporal scales at the military installation.

\section{Study Area}

Our study area was along the southern portion of the Colorado Plateau and primarily located west and northwest of Flagstaff, Arizona, USA (Fig. 1). This area is characterized by Petran Montane Coniferous Forest and Great Basin Conifer Woodland biotic communities (Brown 1994, Spence et al. 1995). Dominant land cover types include ponderosa pine and pinyon pine-juniper (Pinus spp. and $J u$ niperus spp.) woodlands with a mixed understory of Gambel oak (Quercus gambelli) and New Mexican locust (Robinia neomexicana). Higher elevations are dominated by Douglasfir (Pseudotsuga menziesii), and white fir (Abies concolor). Elevation ranged from $408 \mathrm{~m}$ in the southern extent to $2874 \mathrm{~m}$ in the central and eastern extents. Average annual precipitation was $553 \mathrm{~mm}$, with temperatures ranging between an average low of $0.27{ }^{\circ} \mathrm{C}$ and an 


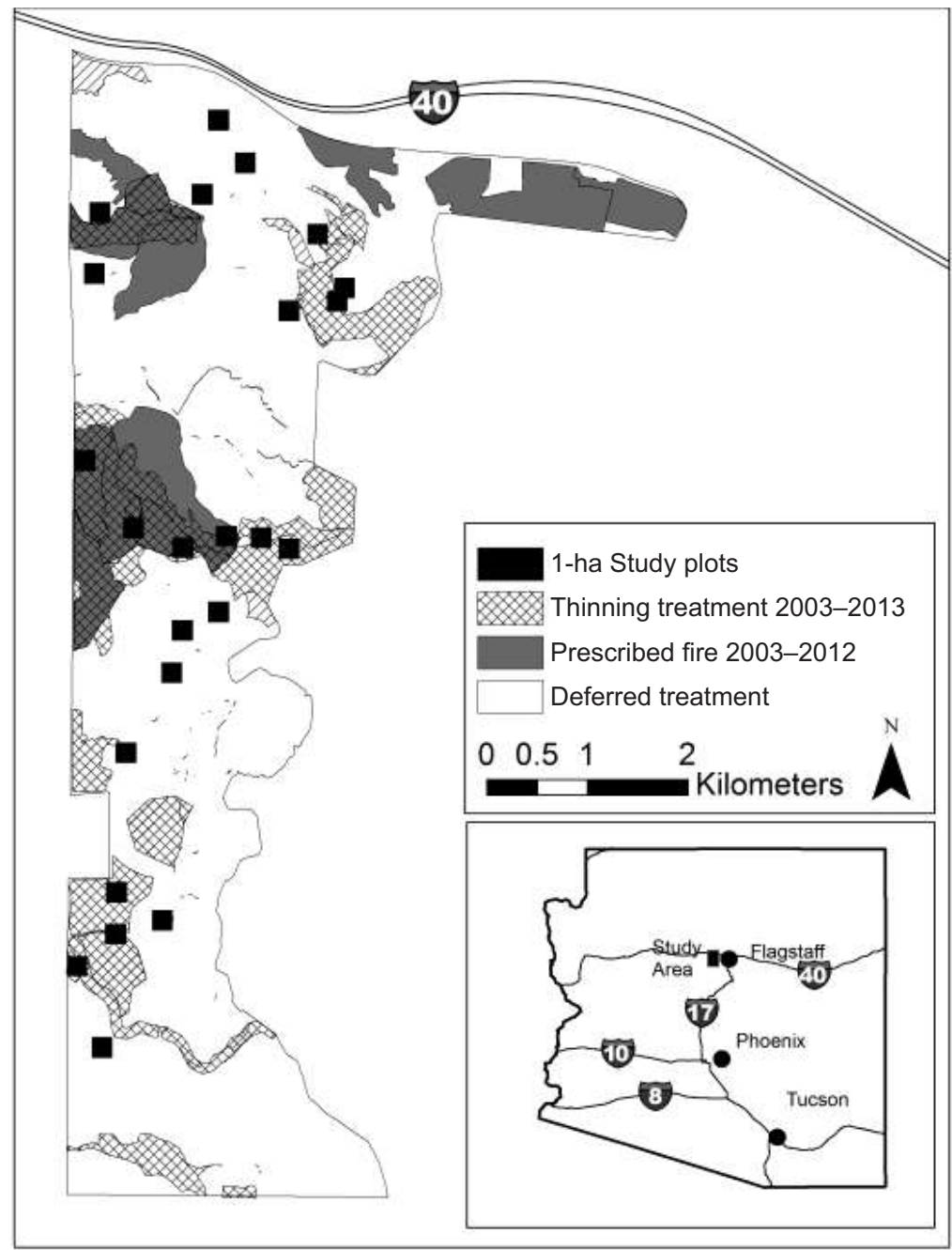

Fig. 1. Plot locations $(n=24)$ and timber management treatments at Camp Navajo in northern Arizona between 2005 and 2012. Each 1-ha plot had 6 random trees where artificial bat boxes were established for trapping.

average high of $16.44{ }^{\circ} \mathrm{C}$ (NOAA 2013). Bats were captured on Camp Navajo, a 11,522-ha Department of Defense (DoD) installation operated by the Arizona Army National Guard, located approximately $16 \mathrm{~km}$ west of Flagstaff.

\section{METHODS}

We designed a mark-and-recapture study using artificial roost structures and a stratified random sample design across 3 timber management strategies (defer [no treatment], thin, and thin and burn). These locations are based on a secondary study that is currently underway and are presented solely to elucidate our sampling design (Fig. 1). Within each of these 3 strata we randomly selected eight 1-ha study plots. Within each study plot we designated 6 ponderosa pines $(>40 \mathrm{~cm}$ DBH) as sample locations. We installed 4 wedgestyle wooden bat boxes on each of the sample trees at the 4 cardinal directions (east, west, north, and south) (Fig. 2). Bat boxes were installed $4.5 \mathrm{~m}$ from the base of each sample tree following the methods established by Tuttle and Hensley (1993). We installed a total of 576 bat boxes within the project area. We installed 288 synthetic roosting structures in the spring of 2004 and an additional 288 in the spring of 2005 . 


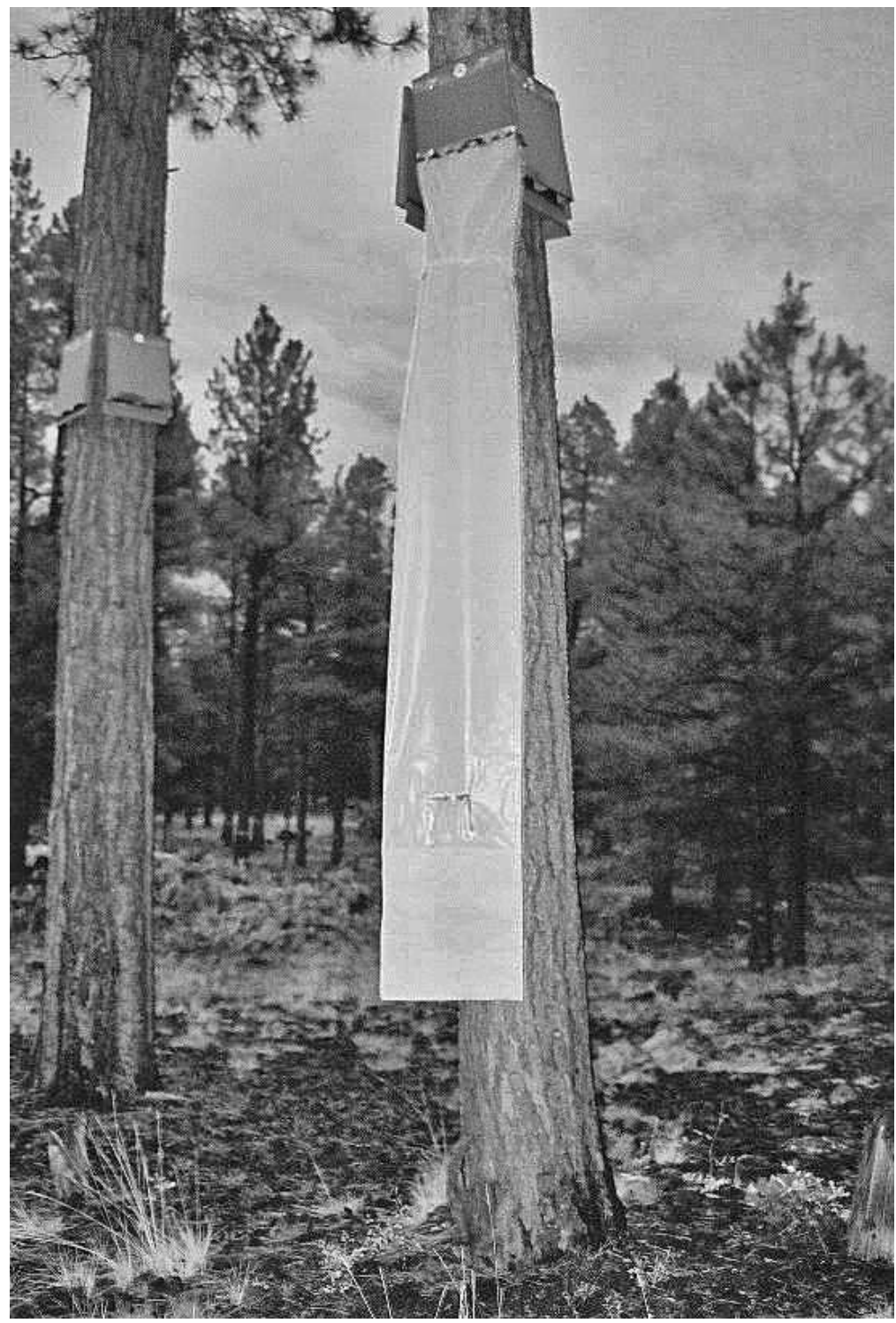

Fig. 2. View of 2 sample trees and the 4 synthetic roosting structures on each tree. View also represents our funneltrap bag used to remove bats from the roost during trapping efforts on Camp Navajo in northern Arizona between 2005 and 2012.

We sampled each bat box 3-5 times between May and October of each survey year. We used a standardized sampling methodology to survey bat boxes between 2005 and 2012; however, we did not survey boxes during 2010. Our methodology consisted of capturing bats at the roosting structures and marking them with alphanumeric modified sparrow, finch, and warbler bird bands. Bird bands were clipped and filed down to reduce the potential for band-related injury. Over the 7-year sampling period of this study, we detected no direct negative impact of the bands on the health of the sample animals. We also used a secondary color-coding system to identify species and capture location. We sampled bats using the methods established by Kunz and Kurta (1988). These methods consisted of attaching a funnel trap to the base of the roosting structure prior to bat 
egress (Fig. 2). We then returned posttwilight to the roost structures to process and band the bats captured within the funnel trap. We recorded demographic (age and sex) and morphological (forearm length, weight, etc.) variables from each bat captured.

We used the presence and absence of individual marked bats detected within the study area to estimate the following parameters: apparent survival, recapture probability, population size, number of survivors, and recruitment. We collapsed presence and absence data into a single record for each individual per year. For example, if an individual was captured once or several times in a survey year we represented it as a presence event " 1. ." Absence events "0" occurred when an individual was not detected during any of the sampling periods within that year. We then used the presence and absence data derived from our mark-recapture surveys to create a Cormack-Jolly-Seber (CJS) model to deal with the open population-based parameters of these 2 study populations. The CJS model is the most commonly used model to explore open populations and has been suggested as a suitable tool for investigating bat populations (Keen 1988, Lebreton et al. 1992). Assumptions of the model include the following: all bats had the same probability of capture (capture heterogeneity); all animals within a species had the same probability of survival from one sample to the next; no bands were lost or missed; and all samples are instantaneous and release was made right after sampling (Lettink and Armstrong 2003). To estimate apparent survival $(\varnothing)$ and recapture probability (p), we calculated a series of CJS models in program MARK. Specifically, we compared 3 a priori models: (1) $\varnothing$ (gender + year) $\mathrm{p}$ (gender + year), (2) $\varnothing$ (gender) $\mathrm{p}$ (gender), and (3) $\varnothing$ (year) p(year). We ranked these models according to their Akaike's information criterion (AIC; Akaike 1973). Models with $\mathrm{AIC}_{c}$ $\leq 2$ were considered to be well supported by the data, and the model with the lowest AIC value was identified as the best-fit model (Burnham and Anderson 1998). We calculated $\mathrm{AIC}_{c}$ difference $\left(\Delta \mathrm{AIC}_{c}\right)$ and Akaike weight (Buckland et al. 1997) for each model to assess model uncertainty and the likelihood of each candidate model, given the data. We then took the best-fit model and estimated population size, number of survivors, and recruitment using the top-performing model. We estimated the population for each year using the equation

$$
N_{i}=n_{i} / p_{i},
$$

where $N_{i}$ was the estimated population size for occasion $i, n_{i}$ was the number of bats captured on occasion $i$, and $p_{i}$ was the recapture probability for occasion $i$ (Lebreton 2009, Williams et al. 2002). We estimated number of survivors using the equation

$$
\text { number of survivors }=\emptyset_{i} * N_{i} \text {, }
$$

where $\varnothing_{i}$ was apparent survival for capture occasion $i$ and $N_{i}$ was the estimated population size for capture occasion $i$. We estimated recruitment using the equation

$$
\beta_{i}=N_{i}-\left(\varnothing_{i} * N_{i-1}\right),
$$

where $\beta_{i}$ was the recruitment for occasion $i, N_{i}$ was the estimated population size for occasion $i, \varnothing_{i}$ was the apparent survival for capture occasion $i$, and $N_{i-1}$ was the estimated population size for the capture occasion prior to occasion $i$ (Lebreton 2009). Since we used an open population model, our findings do not discriminate between births and immigration events or between deaths and emigration events.

\section{RESULTS}

Over the 7-year collection period of this study, we banded a total of 529 big brown bats. Captures increased steadily from a low of 23 in 2005 to a peak of 246 in 2012. During 2005 , the number of female bats was approximately equal to the number of males captured. In 2006 and 2007, we captured 25\% more females than males. By 2008 we were capturing $60 \%$ more females than males and by 2009 we were capturing $120 \%$ more females than males. This same female-skewed capture pattern continued in 2011 and peaked in 2012 at $180 \%$ more females than males. We banded 307 individuals that were never recaptured. We recaptured 140 big brown bats only once, and we recaptured 46 bats twice, 20 bats 3 times, 12 bats 4 times, 3 bats 5 times, and 1 bat 6 times.

We banded 227 Arizona myotis during the 7 -year term of this study. Bats banded varied from a low of 36 in 2005 to a peak of 63 in 
TABLE 1. The 3 a priori models developed to describe the factors affecting survival $(\varnothing)$ and recapture probability $(\mathrm{p})$ of big brown bats (Eptesicus fuscus) and Arizona myotis (Myotis occultus) at Camp Navajo in northern Arizona between 2005 and 2012.

\begin{tabular}{lccc}
\hline Model & AIC & $\Delta$ AIC & $w$ \\
\hline Big brown bat & & & \\
$\emptyset$ (gender + year) p(gender + year) & 1311.97 & 0.00 & 0.67 \\
$\emptyset$ (gender) p(gender) & 1308.12 & 3.85 & 0.16 \\
$\varnothing$ (year) p(year) & 1307.89 & 4.08 & 0.17 \\
Arizona myotis & 519.35 & 0.00 & 0.59 \\
$\varnothing$ (gender + year) p(gender + year) & 517.02 & 2.33 & 0.28 \\
$\varnothing$ (year) p(year) & 517.94 & 1.41 & 0.13 \\
$\varnothing$ (gender) p(gender) & & \\
\hline
\end{tabular}

2011. We consistently captured more females than males in all survey years. During 2006, 2007 , and 2009, we captured $80 \%$ more female than male Arizona myotis. Across 2005, 2008, 2011 , and 2012, female capture rates varied from $60 \%$ more females in 2005 to just $16 \%$ more in 2012. We banded 165 Arizona myotis that were never recaptured. Of the remaining 62 Arizona myotis, we recaptured $35,13,10$, 3 , and 1 bat during surveys $1-5$, respectively.

We ran 3 a priori CJS models for big brown bats and Arizona myotis. For both species the best-fit model was the combination of year and sex (Table 1). The best-fit model for big brown bats had a model weight of 0.67 , whereas the 2 lower-ranked models had weights of only 0.17 and 0.16 for sex and year, respectively. The top-ranked model for Arizona myotis was the combination of sex and year and had a model weight of 0.59 , whereas the 2 lower-ranked models had weights of 0.28 and 0.13 for year and gender, respectively. We used these top-fit models to estimate the apparent survival and capture probability for big bats and Arizona myotis.

Apparent survival for big brown bats varied across year and sex (Fig. 3). Apparent survival peaked for female big brown bats between 2005 and 2006 and between 2006 and 2007 for males. Apparent survival was lowest for both genders between 2007 and 2008 (Fig. 3). Mean apparent survival was 0.33 (SD 0.17) for males and 0.64 (SD 0.19) for females. Apparent survival was significantly higher for females across survey years $(P=0.034)$.

Capture probability for big brown bats varied across survey year and gender (Fig. 4). Recapture probability peaked for females between 2011 and 2012 and for males between 2007 and 2008. The lowest recapture probability was between 2005 and 2006 for both sexes (Fig. 4). The mean recapture probability was 0.28 (SD 0.14) for females and 0.17 (SD 0.72 ) for males. Recapture probabilities did not vary significantly between genders across survey years ( $P=0.084$; Fig. 4). Capture probabilities for big brown bats were lowest for males and females during 2006 and peaked for both genders in 2012 (Table 2). Females were captured in higher numbers than males in all survey years. Capture ratios were nearly 2 females per male from 2009 to 2012 (Table 2). We recaptured a mean of 39 (SD 23) males per year and 68 females (SD 49). Females had a significantly higher recapture rate than males $(P=0.05)$.

Estimated population size for both female and male big brown bats was lowest in 2008 and peaked for males in 2012 and females in 2011 (Table 2). The mean estimated population across years was 247 (SD 143) for males and 236 (SD 124) for females. We detected no significant difference between male and female estimated population sizes $(P=0.83)$.

The estimated number of survivors was lowest from 2007 to 2008 for both male and female big brown bats. The number of survivors was highest between 2006 and 2007 for females and between 2008 and 2009 for males (Table 2). The mean number of survivors was 65 (SD 35) for males and 76 (SD 52) for females. We detected no significant difference in number of survivors between sexes of big brown bats $(P=0.669)$.

Estimated recruitment for male big brown bats was lowest between 2008 and 2009 and peaked between 2011 and 2012. Females exhibited peak recruitment between 2011 and 2012 and lowest recruitment from 2006 to 2007 and 2008 to 2009 (Table 2). Mean recruitment was 135 (SD 52) for males and 141 (SD 99) for females. Recruitment did not vary significantly between males and females across survey year $(P=0.868)$. 


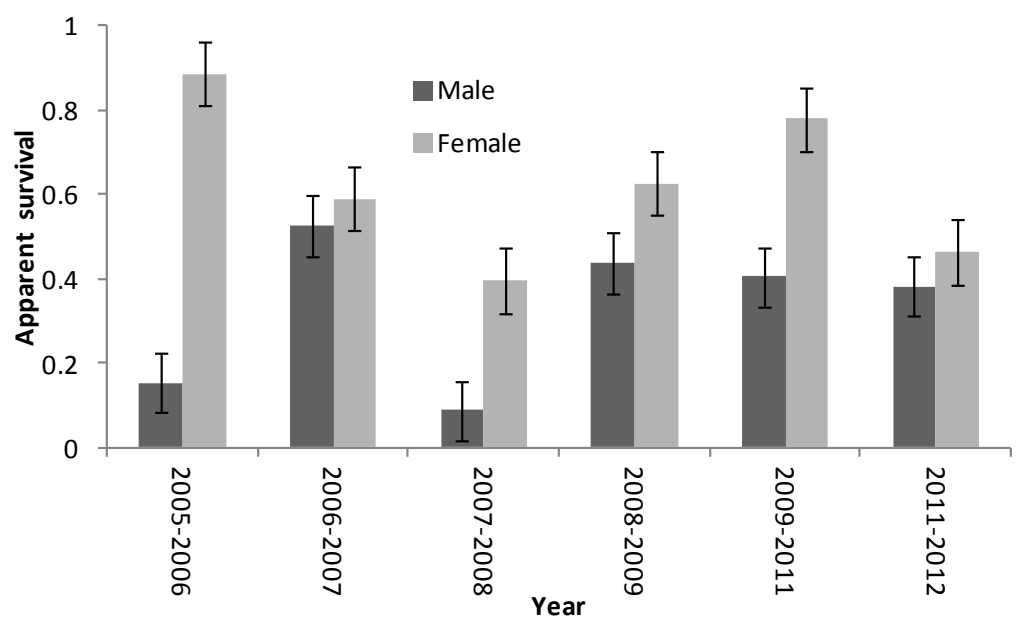

Fig. 3. Model average overwinter survival of male and female adult big brown bats (Eptesicus fuscus) on Camp Navajo in northern Arizona between 2005 and 2012. Error bars represent standard error.

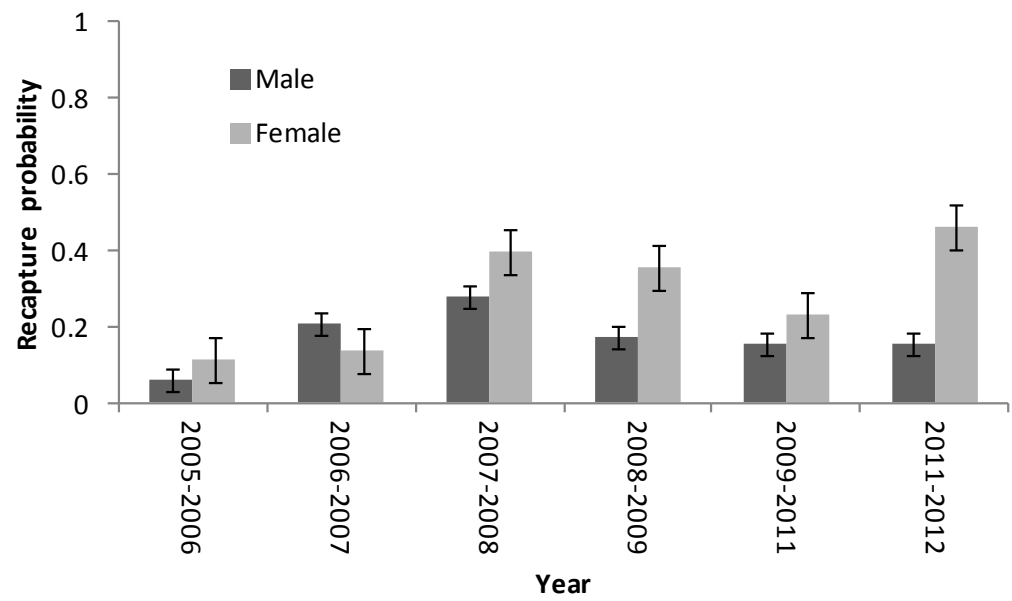

Fig. 4. Model average recapture probability of male and female adult big brown bats (Eptesicus fuscus) on Camp Navajo in northern Arizona between 2005 and 2012. Error bars represent standard error.

Apparent survival of Arizona myotis varied across sex and survey year (Fig. 5). Survival was lowest between 2007 and 2008 for females and between 2009 and 2011 for males. Apparent survival peaked for females between 2009 and 2011 and for males between 2006 and 2007 (Fig. 5). Female Arizona myotis had an apparent survival of 0.64 (SD 0.17) and males 0.45 (SD 0.32 ). Apparent survival did not vary significantly across $\operatorname{sex}(P=0.36)$.

Arizona myotis capture probability varied across survey year and sex (Fig. 6). Female and male capture probability peaked between 2008 and 2009. Capture probability was lowest between 2005 and 2006 for females and between 2006 and 2007 for males (Fig. 6). The mean capture probability across survey years was 0.63 (SD 0.18) for females and 0.44 (SD 0.23) for males. Capture probability did not vary significantly between male and female Arizona myotis $(P=0.069)$.

Arizona myotis recaptures varied across survey years and sex (Table 3). Male and female recaptures peaked in 2011. Recaptures were lowest for male Arizona myotis in 2007 and for females in 2008 (Table 3). Females 
TABLE 2. Big brown bat (Eptesicus fuscus) recaptures across years, estimated population size across years, estimated number of survivors between years, and estimated recruitment between years at Camp Navajo in northern Arizona between 2005 and 2012 .

\begin{tabular}{lcccccr}
\hline & \multicolumn{6}{c}{ Year/period } \\
\cline { 2 - 7 } Recaptures & 2006 & 2007 & 2008 & 2009 & 2011 & 2012 \\
\hline Male & 11 & 31 & 27 & 49 & 43 & 77 \\
Female & 12 & 39 & 35 & 79 & 94 & 147 \\
\hline Estimated population size & 2006 & 2007 & 2008 & 2009 & 2011 & 2012 \\
\hline Male & 179 & 149 & 97 & 286 & 275 & 497 \\
Female & 104 & 278 & 88 & 222 & 407 & 317 \\
\hline Estimated number of survivors & $2005-2006$ & $2006-2007$ & $2007-2008$ & $2008-2009$ & $2009-2001$ & $2011-2012$ \\
\hline Male & 59 & 42 & 20 & 123 & 65 & 81 \\
Female & 39 & 164 & 16 & 78 & 99 & 61 \\
\hline Estimated recruitment & $2005-2006$ & $2006-2007$ & $2007-2008$ & $2008-2009$ & $2009-2001$ & $2011-2012$ \\
\hline Male & $*$ & 121 & 106 & 77 & 163 & 210 \\
Female & $*$ & 65 & 113 & 72 & 144 & 308 \\
\hline
\end{tabular}

*No estimated population sizes were calculated in 2005 for subsequent recruitment calculations.

were recaptured at a mean rate of $30(\mathrm{SD}$ 4.37) per year, and males were recaptured at a mean rate of 19 (SD 5.98) per year. We recaptured females at a significantly $(P=0.008)$ higher rate across survey years than males.

The estimated population size of Arizona myotis varied across year and sex (Table 3 ). The lowest estimated population size for both genders occurred during 2009. Estimated population peaked for male Arizona myotis during 2007 at a level 2-3 times higher than in all other years (Table 3). The peak estimated population for females occurred during 2006 and remained fairly flat through the survey period. The mean population estimate for male Arizona myotis was 59 (SD 43.22). The mean population estimate for female Arizona myotis was 50 (SD 11.75) bats. The estimated population size of female and male Arizona myotis did not vary significantly across survey years $(P=0.636)$.

The estimated number of Arizona myotis survivors varied across year and gender (Table $3)$. The number of male survivors peaked between 2006 and 2007 at a level 5 times higher than in any other year (Table 3). The peak number of female survivors occurred between 2005 and 2006. Estimated number of surviving Arizona myotis reached its low for females between 2007 and 2008, and for males between 2009 and 2011 (Table 3). Mean estimated number of survivors for female Arizona myotis across survey years was 32 (SD 10.58). Males had a mean estimated number of survivors across years of 34 (SD 46.92). We detected no significant difference between the sexes for the estimated number of survivors across survey years $(P=0.922)$.

Estimated recruitment of Arizona myotis varied across sex and survey year (Table 3 ). Male recruitment peaked between 2009 and 2011 and female recruitment between 2011 and 2012. Male recruitment was lowest between 2007 and 2008, and female recruitment was lowest between 2009 and 2011 (Table 3). Mean estimated recruitment for male Arizona myotis was 24 (SD 14.19). The mean female recruitment was 18 (SD 11.25). We did not detect any significant difference between genders across survey years $(P=0.507)$.

\section{Discussion}

During the period of this study, we detected trends in apparent survival, capture probabilities, estimated population size, estimated number of survivors, and estimated recruitment for big brown bats and Arizona myotis on Camp Navajo. These trends provide an estimate of baseline population characteristics for these 2 species on Camp Navajo. This baseline can be used to detect abrupt changes in population characteristics due to factors such as WNS, catastrophic wildfires, or any other broad-scale habitat alteration that leads to destabilization of these bat populations. Our findings demonstrate that population characteristics vary across survey year and sex within these 2 species. 


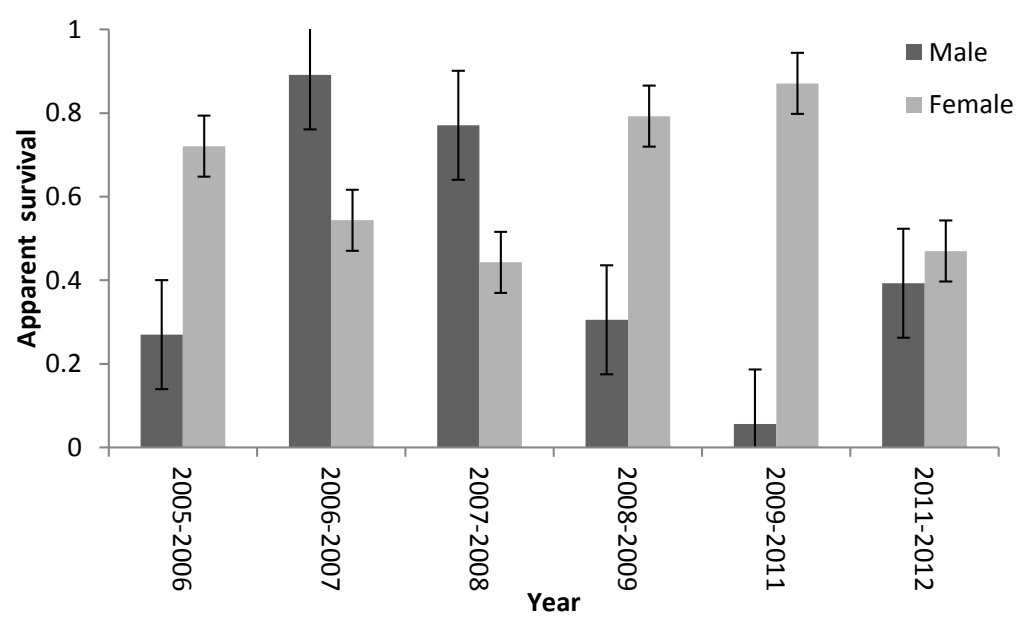

Fig. 5. Model average overwinter survival of male and female adult Arizona myoits (Myotis occultus) on Camp Navajo in northern Arizona between 2005 and 2012. Error bars represent standard error.

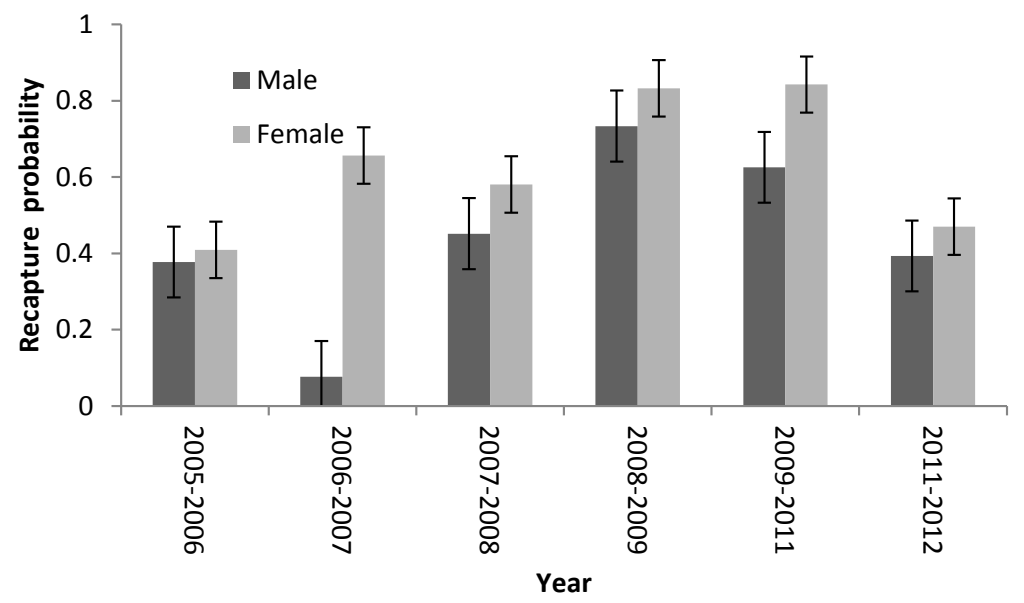

Fig. 6. Model average recapture probability of male and female adult Arizona myotis (Myotis occultus) on Camp Navajo in northern Arizona between 2005 and 2012. Error bars represent standard error.

Big brown bat populations within the project area appeared to be in a positive growth phase from 2005 to 2012 . This population growth was characterized by increases in the number of individuals of both genders recaptured in each successive sampling year. The number of big brown bat recaptures increased an order of magnitude between 2005 and 2012. This population increase was also observed in the redoubling of female big brown bats recaptured between 2008 and 2012. The high apparent survival of females also indicates that the big brown bat population is likely in a colonization phase of this synthetic habitat.

Apparent survival for male big brown bats was half that of the females. The significantly higher apparent survival of female big brown bats indicates that either male mortality was much higher than female mortality or male migration into and out of the study area was much higher. The low apparent survivorship for male big brown bats was likely a function of roost fidelity rather than mortality (Lausen and Barclay 2002). Capture probability also indicates that female big brown bats have a 
TABLE 3. Number of recaptures, estimated population size across years, estimated number of survivors between years, and estimated recruitment between years for Arizona myotis (Myotis occultus) at Camp Navajo in northern Arizona between 2005 and 2012 .

\begin{tabular}{lcccccc}
\hline & \multicolumn{6}{c}{ Year/period } \\
\cline { 2 - 7 } Recaptures & 2006 & 2007 & 2008 & 2009 & 2011 & 2012 \\
\hline Male & 15 & 11 & 19 & 19 & 27 & 25 \\
Female & 28 & 32 & 24 & 34 & 36 & 29 \\
\hline Estimated population size & 2006 & 2007 & 2008 & 2009 & 2011 & 2012 \\
\hline Male & 40 & 143 & 42 & 26 & 43 & 64 \\
Female & 68 & 49 & 41 & 41 & 43 & 62 \\
\hline Estimated number of survivors & $2005-2006$ & $2006-2007$ & $2007-2008$ & $2008-2009$ & $2009-2001$ & $2011-2012$ \\
\hline Male & 11 & 127 & 32 & 8 & 2 & 25 \\
Female & 49 & 26 & 18 & 32 & 37 & 29 \\
\hline Estimated recruitment & $2005-2006$ & $2006-2007$ & $2007-2008$ & $2008-2009$ & $2009-2001$ & $2011-2012$ \\
\hline Male & $*$ & 16 & 10 & 18 & 41 & 39 \\
Female & $*$ & 22 & 23 & 8 & 6 & 33 \\
\hline
\end{tabular}

*No estimated population sizes were calculated in 2005 for subsequent recruitment calculations.

higher roost fidelity than males of the species. This pattern of differential roost fidelity was also noted by Lausen and Barclay (2002). The lowest recapture probability for both genders occurred during the first recapture season postmarking. As the project moved forward, capture probabilities increased through 2007-2008 for the males and 2011-2012 for females. Recruitment was lowest in 2008 2009 , indicating some unknown stressor on the reproduction of big brown bats on or adjacent to the study area. Estimated recruitment was the product of a composite of birth and immigration. Thus, during 2008-2009, some factor limited immigration and or births during that period. Just prior to the low-recruitment year, we had the lowest number of estimated survivors (2008). We also had the lowest estimated population of big brown bats in 2008 , indicating that death or emigration also contributed to the low recruitment during 2008-2009. The population for both male and female big brown bats had reached a peak after this low recruitment by 2011 and 2012, respectively. Increasing capture probability for females, along with the high apparent survival and peak estimated recruitment in 2012, indicates that female big brown bats have a higher fidelity to the study area than the males.

The highest roost fidelity for bats is generally to the maternity roost (Kunz and Fenton 2003). As late as 1986, no maternity colonies of big brown bats were known from Arizona (Hoffmeister 1986). Adams predicted that this lack of records was a function of survey effort rather than the actual absence of maternity colonies in Arizona (Adams 2003). The number of female recaptures has steadily increased from 2006 and reached its highest point in 2012. By 2009, females were recaptured at a rate double that of males. We also began capturing more than a dozen female big brown bats in several of our sampling locations, indicating maternity roosting. The apparent high roost fidelity of females, coupled with the increasing number of recaptures, indicates that female big brown bats are utilizing the study site as maternity habitat, while males appear to be more transient.

Arizona myotis, unlike the big brown bats within our study area, appear to have remained in a more static population growth phase. As with big brown bats, we captured more female Arizona myotis than males, and male Arizona myotis appear to have generally lower site fidelity than females. We also detected several trends that provide us with a broader understanding of Arizona myotis populations in northern Arizona.

Apparent survival, recapture probability, and population estimates indicated that male and female bats responded across years differentially. In the period during which we would have expected apparent survivorship to be the lowest, 2009-2011, we saw the highest female apparent survival. In that same period, we saw the lowest apparent survival for male Arizona myotis. We did not detect a significant 
difference between male and female apparent survivorship. We did, however, observe much lower variability in female apparent survivorship than in male apparent survivorship. The recapture probability for Arizona myotis also supports the findings that female Arizona myotis have a higher fidelity to the study site than their male counterparts. Capture probabilities for both sexes peaked in 2008-2009. This peak in recapture probability indicates that favorable habitat conditions provided increased survivorship between 2008 and 2009. We recaptured female Arizona myotis at a significantly higher rate than males across years within this study. Our population estimates also detected higher study site fidelity for females than males. We detected eruptive immigration and emigration events with our population estimates. The estimated population was lowest in 2009 for both females and males, indicating some population-level impact due to habitat alteration or climatic pressures. In 2007, we saw a $250 \%$ jump in the estimated population of male Arizona myotis in the study area. This population jump appears to be due to a large influx of males from outside of the study area. Arizona myotis appear to be closely tied to forest habitats in northern Arizona. An active fire season in northern Arizona may have led to the displacement of this Arizona myotis population from elsewhere in northern Arizona. This pattern of fluctuation in the male population in the study area was also evident across population estimates in all other survey years. Male population estimates (SD 0.43) had 4 times the variability of female estimates (SD 0.11 ). As with population estimates, the number of survivors was also highly variable for males (SD 47) compared to females (SD 11). The combination of higher recapture of females, high survivorship estimates where we would expect low values, and low variability in female population estimates indicate that females have a higher fidelity to the study area than males.

In this study, we used 7 years of markrecapture data to establish baseline population characteristics for big brown bats and Arizona myotis. We discovered that big brown bats were likely in a colonizing phase, and the study area showed an increase in maternity colonies. We also detected maternity activity with Arizona myotis; however, the population was in a flat growth phase and not increasing. This study provided a measure of population status for these 2 species that can be compared across temporal scales at Camp Navajo. In essence, this study provides the basis for an early warning system for WNS in Arizona. Subsequent data collected for this long-term mark-recapture study can be compared against the baseline apparent survival, recapture probability, estimated population size, estimated number of survivors, and estimated recruitment for the big brown bat and the Arizona myotis. Any significant difference between our calculated baselines for these population characteristics should be used as an early warning of population decline.

\section{ACKNOWLEDGMENTS}

We thank the Arizona National Guard for its role in project development and funding. Funding was provided through Interagency Service Agreement M11-0021 between the Arizona Department of Emergency and Military Affairs and the Arizona Game and Fish Department (Project \# AZ655060043). We also thank Tim Wade, Ray Schweinsburg, Michael F. Ingraldi, Renee Wilcox, and Pam Kennedy, Wildlife Contracts Branch, Arizona Game and Fish Department, for project administration, development, and draft review. Keith Sullivan, Lias Hastings, and Woodrow Crumbo provided field support and data entry.

\section{Literature Cited}

ADAms, R.A. 2003. Bats of the Rocky Mountain West: natural history, ecology, and conservation. University of Colorado Press, Boulder, CO.

Agosta, S.J. 2002. Habitat use, diet and roost selection by the big brown bat (Eptesicus fuscus) in North America: a case for conserving an abundant species. Mammal Review 32:179-198.

AKAIKE, H. 1973. Information theory and an extension of the maximum likelihood principle. Pages 267-281 in B.N. Petrov and F. Csaki, editors, Proceedings of the 2nd International Symposium on Information Theory, Akademiai Kiado, Budapest. (Reproduced: Pages 610624 in S. Kotzand and L.S. Johnson, editors. 1992. Breakthroughs in statistics. Volume 1, Foundations and Basic Theory. Springer-Verlag, New York.)

Blehert, D.S., A.C. Hicks, M. Behr, C.U. Meteyer, B. Berlowski-Zier, E.L. Buckles, J.T.H. Coleman, S.R. Darling, A. Gargas, R. Niver, et al. 2009. Bat white-nose syndrome: an emerging fungal pathogen? Science 323(5911):227.

BRown, D.E., EDITOR. 1994. Biotic communities: southwestern United States and northwestern Mexico. University of Utah Press, Salt Lake City, UT. 
Buckland, S.T., K.P. Burnham, and N.H. Augustin. 1997. Model selection: an integral part of inference. Biometrics 53:603-618.

Burnham, K.P., AND D.R. Anderson. 1998. Model selection and inference. Springer, New York, NY.

Ellison, L.E., T.J. O'Shea, D.J. Neubaum, and R.A. BOWEN. 2007. Factors influencing movement probabilities of big brown bats (Eptesicus fuscus) in buildings. Ecological Applications 17:620-627.

Fenton, M.B, and R.M.R Barclay. 1980. Myotis lucifugus. Mammalian Species 142:1-8.

Findley, J.S., A.H. Harkis, D.E. Wilson, and C. Jones. 1975. Mammals of New Mexico. University of New Mexico Press, Albuquerque, NM.

Hoffmeister, D.F. 1986. Mammals of Arizona. University of Arizona Press, Tucson, AZ.

KEEN, R. 1988. Mark-recapture estimates of bat survival. In: Ecological and behavioral methods for the study of bats. Smithsonian Institution Press, Washington, DC.

KunZ, T.H., AND M.B. Fenton. 2003. Bat ecology. University of Chicago Press, Chicago, IL.

KunZ, T.H., AND A. KuRTA. 1988. Capture methods and holding devices. In: Ecological and behavioral methods for the study of bats. Smithsonian Institution Press, Washington, DC.

Kurta, A.T., AND R.H. BaKer. 1990. Eptesicus fuscus. Mammalian Species 356:1-10.

Lausen, C., and R.M.R. Barclay. 2002. Roosting behavior and roost selection of female big brown bats (Eptesicus fuscus) roosting in rock crevices in southeastern Alberta. Canadian Journal of Zoology 80: 1069-1076.

Lebreton, J.D. 2009. Population dynamics and survivorship in bats. Chapter 8 in Ecological and behavioral methods for the study of bats. 2nd edition. Johns Hopkins University Press, Baltimore, MD.

Lebreton. J.D., K.P., Burnham, J. Colbert, and D.R. ANDERSON. 1992. Modeling survival and testing biological hypotheses using marked animals: a unified approach with case studies. Ecological Monographs 62:67-118

LetTink, M., AND D.P. ARMSTRONG. 2003. An introduction to mark-recapture analysis for monitoring threatened species. Department of Conservation Technical Series 28A, 5-32. Department of Conservation, Wellington, New Zealand.

Neubaum, D.J., M.A. Neubaum, L.E. Ellison, and T.J. O’SHEA. 2005. Survival and condition of big brown bats (Eptesicus fuscus) after radiotagging. Journal of Mammalogy 86:95-98.
Neubaum, D.J., T.J. O’Shea, And K.R. Wilson. 2006. Autumn migration and selection of rock crevices as hibernacula by big brown bats in Colorado. Journal of Mammalogy 87:470-479.

Neubaum, D.J., K.R. Wilson, and T.J. O’Shea. 2007. Urban maternity-roost selection by big brown bats in Colorado. Journal of Wildlife Management 71: 728-736.

[NOAA] National Weather Service. 2013. Weather data. [Accessed Aug 2013]. http://www.nws.noaa.gov/ climate/xmacis.php?wfo $=f g z$

O’Shea, T.J., L.E. Ellison, D.J. Neubaum, M.A. Neubaum, C.A. Reynolds, and R.A. Bowen. 2010. Recruitment in a Colorado population of big brown bats: breeding probabilities, litter size, and firstyear survival. Journal of Mammalogy 91:418-428.

Piaggio, A.J., E.W. Valdez, M.A. Bogan, and G.S. Spicer. 2002. Systematics of Myotis occultus (Chiroptera: Vespertilionidae) inferred from sequences of two mitochondrial genes. Journal of Mammalogy 83: 386-395.

Rabe, M.J., T.E. Morrell, H. Green, J.C. DeVos Jr., and C.R. Miller. 1998. Characteristics of ponderosa pine snag roosts used by reproductive bats in northern Arizona. Journal of Wildlife Management 62: 612-621.

Spence, J.R., W.H. Romme, L. Floyd-Hanna, and P.G. RowLANDS. 1995. A preliminary vegetation classification for the Colorado Plateau. Pages 193-214 in C. Van Riper III, editor, Proceedings of the Second Biennial Conference on Research in Colorado Plateau National Parks. National Park Service Transactions and Proceedings Series NPS/NRNAU/NRTP-95/11.

Tuttle, M.D., And D. Hensley. 1993. Bat houses: the secrets of success. Bats 11:3-14.

WARNER, R.M. 1985. Interspecific and temporal dietary variation in an Arizona bat community. Journal of Mammalogy 66:45-51.

Whitaker, J.O., JR. 1972. Food habits of bats from Indiana. Canadian Journal of Zoology 50:877-883.

Williams, B.K., J.D. Nichols, AND M.J. Conroy. 2002. Analysis and management of animal populations. Academic Press, San Diego, CA.

WiLson, D.E., AND S. RufF. 1999. The Smithsonian book of North American mammals. Smithsonian Institution Press, Washington, DC.

Received 17 March 2014 Accepted 2 December 2014 